\title{
Cis-acting DNA sequence requirements for P-element transposition
}

\author{
Mary C. Mullins, Donald C. Rio, ${ }^{1}$ and Gerald M. Rubin \\ Department of Biochemistry and Howard Hughes Medical Institute, University of California Berkeley, California 94720 USA
}

The $\mathrm{P}$ transposable element of Drosophila melanogaster has a complex array of cis-acting DNA sequences necessary for efficient transposition. At the $3^{\prime}$ end these sequences extend over more than $\mathbf{1 5 0}$ bp and include 11- and 31-bp sequences found repeated in inverted orientation at the $5^{\prime}$ end. The $P$ element's 5 ' end, however, cannot function as its $3^{\prime}$ end. When two $3^{\prime}$ P-element ends are present, the more proximal end is used preferentially. We found also that the duplication of the target site does not appear to play a role in forward transposition.

[Key Words: P elements; Drosophila; transposable element; cis-acting DNA sequences]

Received January 24, 1989; revised version accepted March 4, 1989.

P elements are a class of transposable elements in Drosophila melanogaster that is found in some strains $(\mathbf{P}$ strains) but is absent in others ( $\mathrm{M}$ strains) (Bingham et al. 1982; Rubin et al. 1982). Both the frequency and tissue specificity of their transposition are regulated (for review, see Engels 1989). P elements are of two size classes: an autonomous 2907-bp element that encodes a trans-acting protein, transposase, required for transposition (Karess and Rubin 1984; Rio et al. 1986) and smaller elements apparently derived from the 2.9 -kb element by heterogeneous internal deletions $\left(\mathrm{O}^{\prime}\right.$ Hare and Rubin 1983).

The smaller P elements are nonautonomous; they do not encode transposase but they can be mobilized when supplied with transposase from a $2.9-\mathrm{kb}$ element. Thus, these deleted elements contain all the cis-acting DNA sequences required for transposition. Sequence analysis of several of these elements revealed that not more than $138 \mathrm{bp}$ at the $5^{\prime}$ end and $216 \mathrm{bp}$ at the $3^{\prime}$ end of the $\mathrm{P}$ element are necessary for transposition or excision (O'Hare and Rubin 1983). Contained within these sequences are a perfect terminal inverted repeat (IR) of 31 $\mathrm{bp}$ and an 11-bp sequence found in inverted orientation $\sim 130$ bp from each end (see Fig. 1). The structure and sequence of $P$ elements put them in a class separate from the retrotransposons (Weiner et al. 1986) and suggest that $\mathrm{P}$ elements transpose via a DNA rather than an RNA intermediate.

Outside the termini of nearly all transposable elements are found direct repeats of a few base pairs, which were present in one copy at the genomic site prior to integration of the transposon (for reviews, see Kleckner 1981; Shapiro 1983). For most transposable elements,

'Present address: Whitehead Institute, Cambridge, Massachusetts 02142 USA. there is little sequence specificity for the target DNA. The length of the duplication, however, is characteristic for a given transposable element family and ranges from 1 to $13 \mathrm{bp}$. $\mathrm{P}$ elements generate an 8-bp target-site duplication (O'Hare and Rubin 1983). Although there are hotspots for P-element integration, there is little sequence specificity for the 8-bp target site (Engels 1989).

Definition of the sequences important for transposition may reveal sites where P-element-encoded or cellular proteins interact in the transposition process or where important structural DNA requirements for transposition reside. Here, we investigated the nature of the cis-acting DNA sequences at the 3 ' end of the P element that are required for transposition. We made deletions and a series of clustered-point mutations throughout the P-element $3^{\prime}$ end and determined the ability of these mutated 3 ' ends to function in transposition. This analysis revealed complex sequence requirements at the $3^{\prime}$ end. The 31 -bp inverted repeat (IR) was absolutely required for transposition, whereas mutations of numerous other DNA sequences crippled but did not destroy the activity of the $3^{\prime}$ end. The region required for normal function of the P element extends over $163 \mathrm{bp}$ and is far more extensive than that of most other transposable elements analyzed. Although the $5^{\prime}$ and $3^{\prime}$ ends share some common sequence motifs, the $5^{\prime}$ end could not function as the $3^{\prime}$ end. Finally, the 8 -bp targetsite duplication appeared to play no role in forward transposition.

\section{Results and discussion}

An assay for the cis-acting DNA sequences at the $3^{\prime}$ end To determine the cis-acting DNA sequences for P-element transposition, an assay was needed that could 


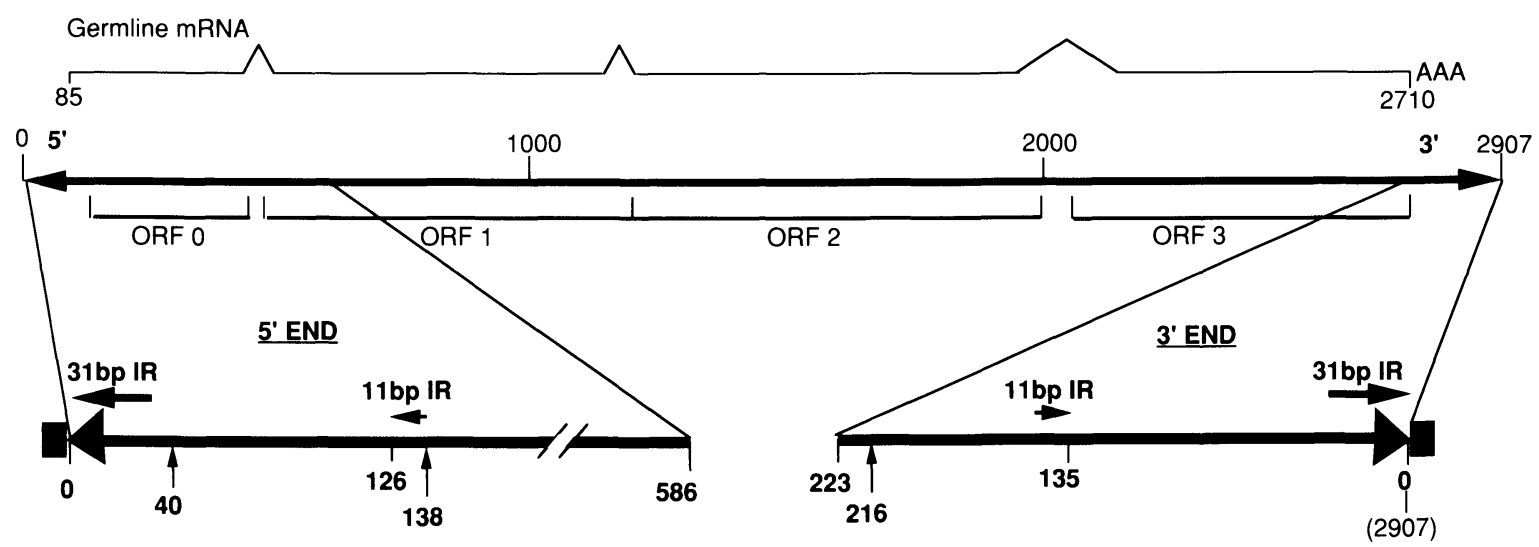

Figure 1. The structure of an autonomous P element. An autonomous 2907-bp P element is shown with its open reading frames (ORF) and the predicted 2.5-kb mRNA as processed in the germ line (Laski et al. 1986). Features of the P-element ends, found in the Carnegie transformation vectors (Rubin and Spradling 1983), are displayed below. Arrows at 138 and 216 bp of the $5^{\prime}$ and $3^{\prime}$ ends, respectively, show the limits of the maximum amount of sequence necessary for transposition as suggested from DNA sequence analysis of internally deleted elements capable of precise excision (O'Hare and Rubin 1983). Within these sequences are the terminal 31-bp IRs and an 11-bp repeat (11-bp IR) located 126 bp and 135 bp from the 5' and 3' ends, respectively. An arrow at 40 bp of the 5' end is the position at which insertion of a DNA fragment containing the rosy gene abolishes transposition (Rubin and Spradling 1983). The stippled boxes adjacent to the P-element ends represent the 8-bp target-site duplication.

compare directly the efficiencies of mutant and wildtype ends. Previous assays were unsatisfactory in that they relied on negative results, that is, the absence of P-element-mediated transformation events following microinjection of the vector DNA into Drosophila embryos (Rubin and Spradling 1983; Karess and Rubin 1984). To overcome this limitation we developed an assay in which transposition occurred with either a mutated or wild-type 3 ' end, and the frequency of use of the mutated end was determined following P-element-mediated transformation of Drosophila embryos. We constructed a vector, $\mathrm{Cgl}-3^{\prime}$ dup, with a single 5' P-element end and two $3^{\prime}$ P-element ends separated by dominant marker genes (see Fig. 2). Between the $5^{\prime}$ end and the proximal $3^{\prime}$ end is the rosy gene and between the two $3^{\prime}$ ends is the bacterial chloramphenicol acetyltransferase (CAT) gene. The Cg1-3'dup element is nonautonomous and therefore transposase was supplied in trans by a helper plasmid. The $5^{\prime}$ end transposed using either the proximal or the distal $3^{\prime}$ end. Both transpositional events resulted in $\mathrm{rosy}^{+}$transformants; however, the two events were distinguished by the absence or presence of the CAT gene. If the proximal end was used in transposition, then the rosy ${ }^{+}$transformant line lacked CAT activity. If the distal end was used then the rosy ${ }^{+}$ line contained CAT activity.

\section{A proximal 3' end transposes in preference to a distal $3^{\prime}$ end}

To compare mutated and wild-type ends, first it was necessary to know the relative frequency with which the two ends were used when both were identical and wild type. We found that the proximal wild-type end was used predominantly; 22 of the 23 transformants did not have CAT activity and therefore used the proximal 223-bp 3' end in preference to the distal end (Fig. 3). Mutated $3^{\prime}$ ' P-element ends were then placed at the proximal $3^{\prime}$ end position while the distal $3^{\prime}$ end was always wild type. Thus, rosy ${ }^{+}$transformants were obtained even if the mutated end was completely inactive. The strong preference for the proximal 3 ' end greatly increased the sensitivity of our assay, because even subtle effects on the efficiency of a given mutant end in transposition should be apparent.

The predominant use of the proximal 3' end cannot be simply a function of its proximity to the $5^{\prime}$ end. In fact, on the circular $\mathrm{Cgl}-3^{\prime}$ dup plasmid the proximal $3^{\prime}$ end is a greater distance from the $5^{\prime}$ end than the distal $3^{\prime}$ end. Although it has been observed that P-element-transformation frequency decreases with increasing DNA length inside the P-element ends (Spradling 1986), the expected differential between an $8-\mathrm{kb}$ and a $10-\mathrm{kb}$ transposon would be small. Indeed, the transformation frequency was not reduced when a nonfunctional $3^{\prime}$ end was placed at the proximal position and transposition occurred using exclusively the distal wild-type $3^{\prime}$ end /see Materials and methods). This observation demonstrates also that the distal 3' end is not in a poor DNA context that inhibits its transpositional activity.

A more proximal $3^{\prime}$ end could be used preferentially by a mechanism unrelated to the distance per se. For example, an initial transposition complex might form at the $5^{\prime}$ end and track unidirectionally on the DNA to the first $3^{\prime}$ end with which it would undergo transposition. In this manner the distal $3^{\prime}$ end would be precluded from use by the more proximal 3 ' end. A nonfunctional proximal $3^{\prime}$ end would not permit establishment of a final transposition complex and instead the tracking would continue to the distal $3^{\prime}$ end. Such tracking of protein complexes along DNA has been invoked in the Tn3 resresolvase recombination reaction (Kitts et al. 1983; 


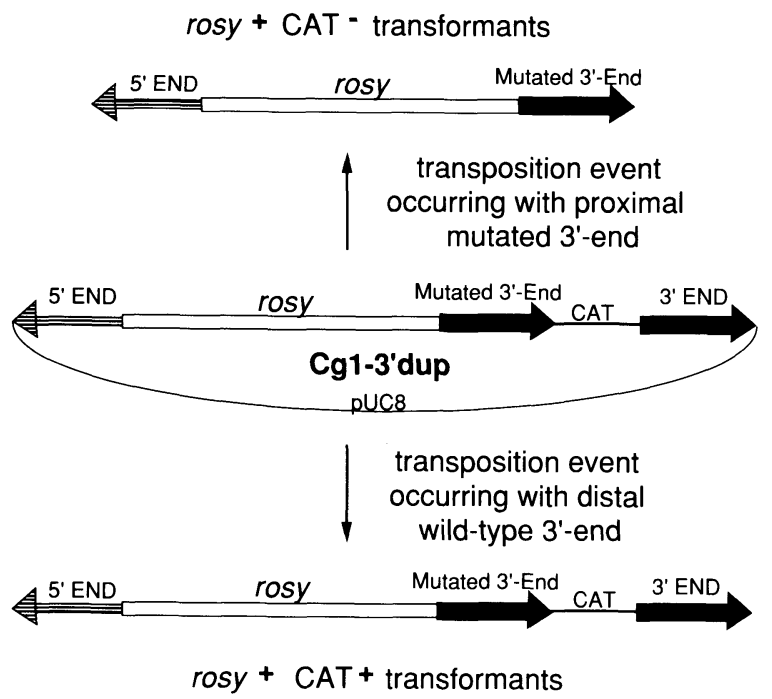

Figure 2. A transposition assay for mutated $3^{\prime}$ P-element ends. In the vector Cg1-3'dup both the $5^{\prime}$ end and the distal $3^{\prime}$ end are wild type. Mutated $3^{\prime}$ ends were placed at the proximal position. Cgl-3'dup was coinjected with a transposase-helper plasmid into rosy ${ }^{506}$ embryos. rosy ${ }^{+}$transformants were isolated in the next generation and assayed for CAT activity to determine which $3^{\prime}$ end was used in transposition. The two possible events are shown above and below the Cgl-3'dup vector.

Krasnow and Cozzarelli 1983; Benjamin et al. 1985; Wasserman et al. 1985), although more recent results suggest a model based on DNA topology (Craigie and Mizuuchi 1986; Benjamin and Cozzarelli 1988). Alternatively, transposition complexes might form equally well with either $3^{\prime}$ end, each of which would mediate DNA breakage outside its end as part of a normal transposition event. DNA breakage adjacent to the proximal $3^{\prime}$ end would prevent use of the distal $3^{\prime}$ end and thus a functional proximal $3^{\prime}$ end would be used preferentially.

We assume that a decrease in use of the proximal $3^{\prime}$ end reflects a decrease in the activity of that end in transposition. Because the mechanism for preferential use of the proximal $3^{\prime}$ end is not understood, it is possible that a decreased use of the proximal $3^{\prime}$ end could reflect a decrease in the ability of the proximal end to inhibit the use of the distal end. It is formally possible that such an inhibitory function might occur independently of transpositional activity.

\section{$163 \mathrm{bp}$ at the $3^{\prime}$ end is sufficient for wild-type function}

P-element $3^{\prime}$ ends were mutated in vitro and placed in the internal $3^{\prime}$-end position of the $\mathrm{Cg} 1-3$ 'dup vector. A deletion analysis was performed to determine the limits of the sequences required at the $3^{\prime}$ end. CAT activity was determined on the rosy ${ }^{+}$transformant lines (Fig. 3) and DNA blot hybridization analysis of a subset of these lines confirmed the predicted integration events (data not shown).

Two conclusions can be drawn from these data. First, not more than the terminal $163 \mathrm{bp}$ of the $3^{\prime}$ end were required for wild-type levels of transposition activity in our assay. Second, 126-bp of the $3^{\prime}$ end are sufficient for transposition; however, the activity of the 126-bp end is much reduced compared with wild type and is very dependent on the DNA context. Deletion 126 did not undergo transposition when placed adjacent to the $7-\mathrm{kb}$ rosy DNA fragment in Cg1-3'dup. When two different pieces of spacer DNA or a polylinker sequence were placed between the deletion 126 endpoint and the rosy DNA fragment, transposition was observed with this end. This position effect probably does not represent the fortuitous creation of a negative regulatory element at the junction of the deletion endpoint and the rosy fragment, because the spacer DNAs were inserted 11 bp upstream of the junction sequences and thus did not actually disrupt them. More plausibly, sequences in the adjacent rosy-containing fragment, when placed in close proximity to important P-element sequences, have a cisacting inhibitory effect on the function of the $3^{\prime}$ end in transposition. This effect is reminiscent of the 'poison sequences' often suggested for DNA that for unknown reasons does not transform well with $\mathrm{P}$ elements (Spradling 1986). The 11-bp IR lies outside the 126-bp end and therefore it was not absolutely required for transposition.

\section{Complex sequence requirements at the $3^{\prime}$ end}

To determine more precisely the sequences required for transposition, clustered-point mutations were made spanning the 163-bp region defined by the deletion analysis. Specifically, segments of $\sim 10$ bp of P-element sequences were replaced with $10 \mathrm{bp}$ of non-P-element sequences. These mutant $3^{\prime}$ ends were placed in the Cg1-3'dup vector and assayed as described to determine their ability to function in transposition. The results are shown in Figure 4.

Absence of transposition events with the $\mathrm{p} \pi 25.7$ wings-clipped plasmid (Karess and Rubin 1984) demonstrated previously that sequences within the first $23 \mathrm{bp}$ of the 31-bp IR at the $3^{\prime}$ end are essential for transposition. Mutant 31 disrupts most of the remaining sequences in the 31-bp IR (Fig. 4), and also demonstrated an absolute requirement for sequences within this region of the 31-bp IR. The terminal $16 \mathrm{bp}$ of the 31-bp IR bind a $66-\mathrm{kD}$ Drosophila host protein (Rio and Rubin 1988), although its role in transposition is unclear.

Additionally, there were numerous elements that when singly removed crippled the use of the end but did not abolish its activity completely. Outside the 31-bp IR, there were four distinct regions important for transposition: Region E, the 11-bp IR, Region C, and Region A as described in Figure $4 \mathrm{~b}$. The sizes of these regions range from no more than $46 \mathrm{bp}$ in region $A$ to $9 \mathrm{bp}$ in region $\mathrm{C}$. In all the regions except Region E, clusteredpoint mutations of $7-11 \mathrm{bp}$ impaired transposition. Region $\mathrm{E}$ was revealed only through small deletion mutants. The perfect conservation of the 11 -bp repeat sequence and its position relative to each end suggest a functional importance. Indeed, mutants in these $11 \mathrm{bp}$ 
Figure 3. Transposition ability of a series of deleted $3^{\prime}$ ends. A series of Bal31-derived deletions of the $3^{\prime}$ end were placed in the Cg1-3'dup vector and assayed for their ability to function in transposition. White boxed regions represent sequences from the HindIII rosy-containing DNA fragment. Thick lines with arrowheads indicate 3 '-end sequences. The number of nucleotides of $P$ sequence remaining at the $3^{\prime}$ end is indicated for each deletion endpoint. The fraction of transformants using the proximal $3^{\prime}$ end $\left(\mathrm{CAT}^{-} / \mathrm{CAT}^{-}\right.$and $\mathrm{CAT}^{+}$ transformants) is indicated with the corresponding percentage in parentheses. Deletions retaining 47 bp or 126 bp of the $3^{\prime}$ end did not function; all the transformants contained CAT activity and thus have used the outside wild-type end in preference to the more proximal, mutated end. Results obtained with clustered-point mutations were inconsistent with these deletion data and suggested possible negative cis interactions between the 126-bp P-element $3^{\prime}$ end and the adjacent rosycontaining DNA fragment that preclude the use of the 126-bp end in transposition. To test this hypothesis, two different fragments of bacteriophage $\lambda$ DNA were placed between the deletion 126 end point and the adjacent rosy sequences. Spacer 1 is indicated by a checkered box and contains a 1.25$\mathrm{kb}$ fragment of $\lambda$ DNA. Spacer 2 is indicated by a vertically striped box and contains $784 \mathrm{bp}$ of $\lambda$ DNA. Sequence comparison between the spacer DNA and the P-element ends showed no common sequence motifs. Another deletion to bp 126, E9-C1, was made by a second method (described in Materials and methods), which extended the distance between the P-element-deletion end point and the rosy-containing DNA by 27 bp (stippled box). Deletion 126 with spacers 1 or 2 and mutant E9-Cl functioned in transposition in our assay, but not at wild-type levels, as can be seen by the relative frequencies of $\mathrm{CAT}^{-}$to $\mathrm{CAT}^{+}$transformants for these mutants compared to wild type. This suggests that sequences upstream of bp 126 increase transpositional activity. Included within these upstream sequences is the 11-bp IR. Deletions 143 and 153 also functioned in transposition but are again used at a lower frequency than wild type. Deletion 143 contains 9 bp of the 11 -bp IR and deletion 153 contains the entirety of the 11-bp IR. Although the reduced use of these ends may reflect negative effects of the adjacent rosy DNA, clustered-point-mutagenesis experiments /see text and Fig. 4) demonstrate important P-element sequences in this region. Functionally wild-type ends were observed with deletions 163 and 174.

greatly reduced transposition ability, but did not abolish it.

In Region A, small deletions completely abolished function of the end (constructs 26 and 30). Deletions that removed both Region E and the 11-bp IR (constructs 89-C5, 89-Cl, and E9-Cl) functioned with about the same reduced effectiveness as removal of either region singly. Region E and the 11-bp IR may both be necessary for the same function. Removal of either one alone may inactivate this function and thus removal of both does not have a more severe effect.

Construct E11-D2, which changed $10 \mathrm{bp}$ and deleted $10 \mathrm{bp}$ in the nonessential Region B, behaved as a wildtype end. Thus, a specific distance between the functional elements upstream and downstream of this deletion is not necessary for efficient transposition. Deletion of $5 \mathrm{bp}$ in this same region (construct E11-76) did, however, exhibit slightly less transpositional activity. The differential activity of the two ends may reflect the fact that the 10-bp deletion does not change the overall orientation of the sequences on the DNA helix, whereas the 5-bp deletion in E11-76 places the sequences upstream and downstream of this point on opposite sides of the helix.

Our deletion and clustered-point-mutation analysis demonstrated a complex array of sequence requirements

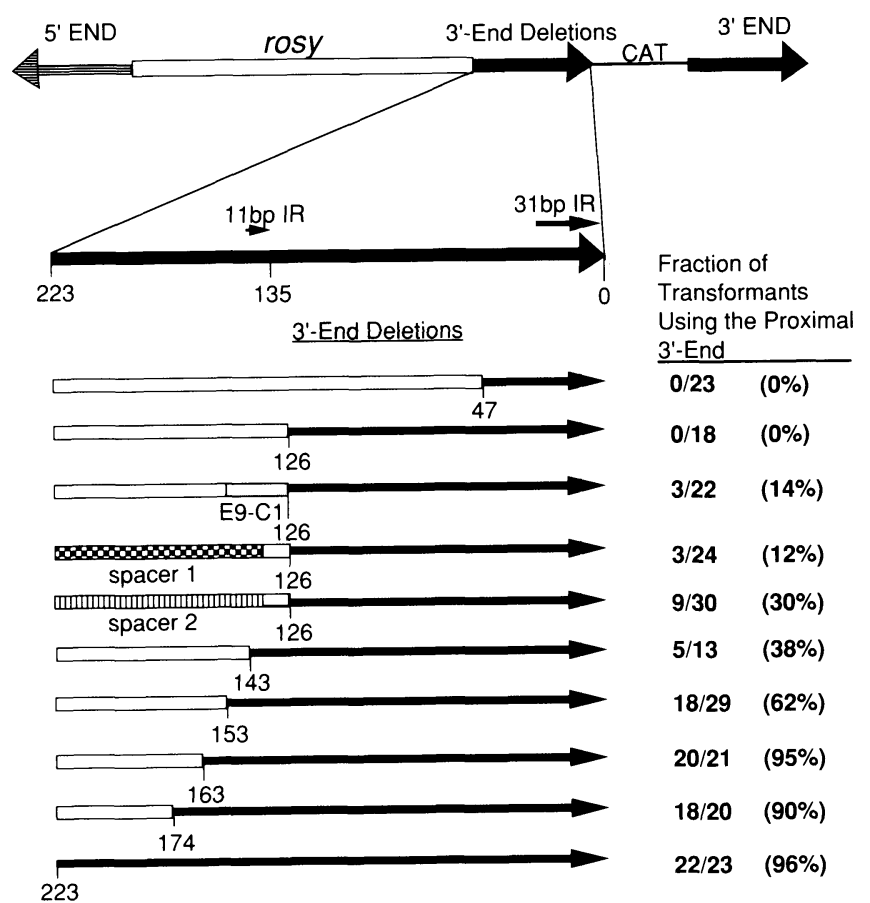

Fraction of Using the Proximal 3'-End $(0 \%)$ $3 / 22 \quad(14 \%)$ $3 / 24 \quad(12 \%)$ (30\%) $18 / 29$ (62\%) 20/21 (95\%) $18 / 20(90 \%)$ $22 / 23 \quad(96 \%)$

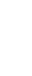

\section{.} (1) (n) 


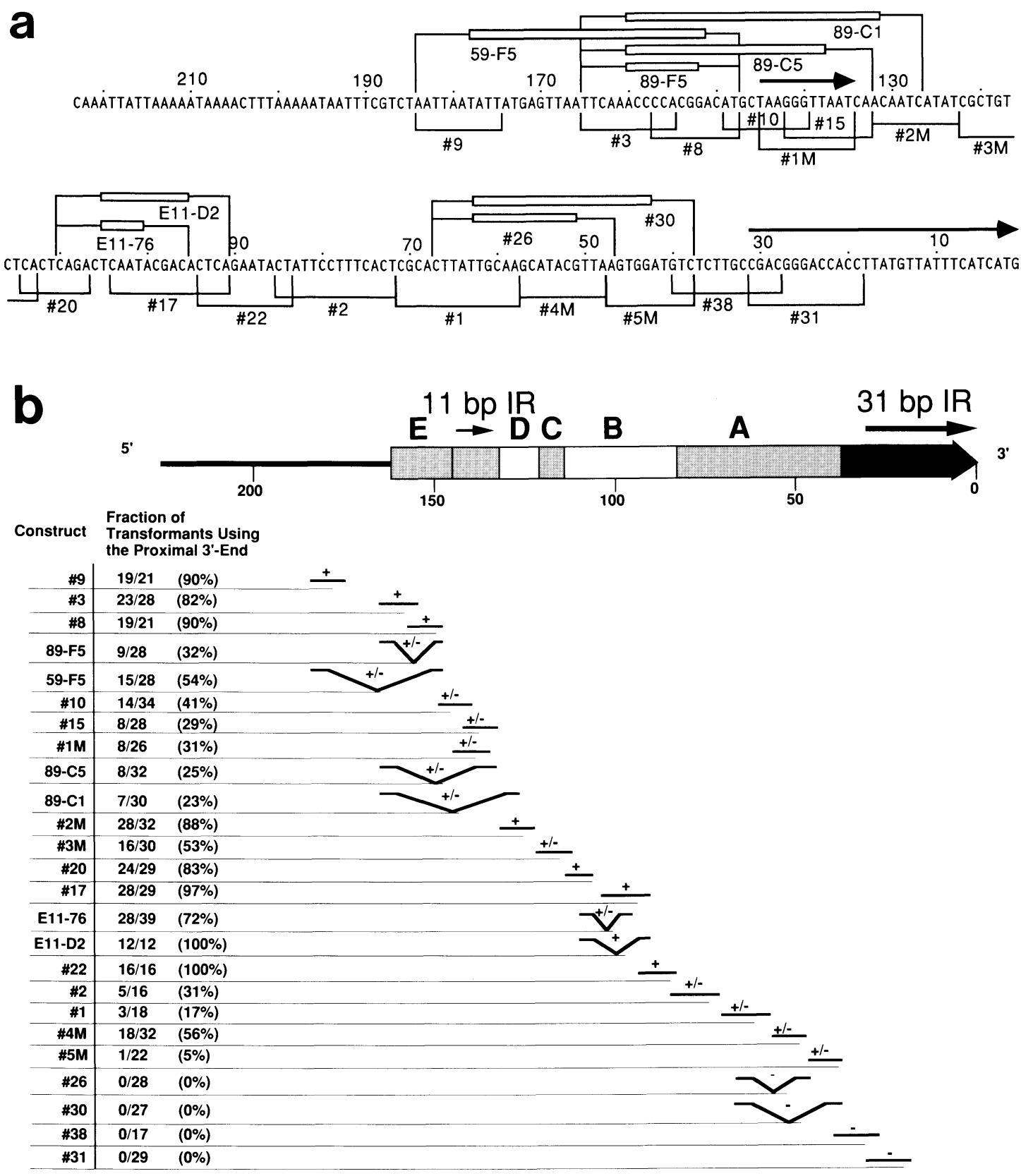

Figure 4. Clustered-point mutants of the $3^{\prime}$ end. (a) The nucleotide sequence of the 223-bp 3'end is shown. The 11- and 31-bp IRs are indicated as thick lines with arrowheads above the sequence. The positions and Cg1-3'dup construct names of the clustered-point mutations are shown below the sequence. The 10-bp clustered-point mutations with small deletions are shown above the sequence. White boxes indicate the extent of the deletion. All sequences upstream and downstream of a given clustered-point mutation remain unchanged. The mutants were made as described in Materials and methods. (b) Analysis of these mutations divided the $3^{\prime}$ end into five domains. Each thick line below the $3^{\prime}$ end indicates the position of the clustered-point mutations. Small deletions are indicated by lines drawn diagonally below the horizontal. The transpositional activity is shown above each mutant: $(+)$ functions as wild type; $(+/-\mid$ functions at a lower frequency than wild type $;(-)$ no detectable function in our assay. The construct name and the fraction of transformants using the proximal $3^{\prime}$ end $\left(\mathrm{CAT}^{-} / \mathrm{CAT}^{-}\right.$and $\mathrm{CAT}^{+}$transformants) are indicated. The corresponding percentage is shown in parentheses. In the diagram of the $3^{\prime}$ end shown at the top of $b$, black-shaded areas represent regions absolutely required for transposition. Stippled areas represent regions with reduced transpositional activity when mutated. White areas are regions that have wild-type transpositional activity when mutated. Mutants corresponding to the given regions are as follows: 38 and 31 in the 31 -bp IR region; 5M, 4M, 1, and 2 in Region A; 22, 17, and 20 in Region B; 3M in Region C; $2 M$ in Region D; 1M, 15, and 10 in the 11-bp IR; 8, 3, 89-F5, and 59-F5 in Region E. 
$52-36$ at the $3^{\prime}$ end with the consensus sequence ATNCACTTA (P. Kaufman and D. Rio, unpubl.). Mutations that overlap this binding site include constructs $4 \mathrm{M}$, $5 \mathrm{M}, 26,30$, and 38 . Clustered-point mutant 38 and small deletions 26 and 30 did not exhibit transpositional activity in our assay. $5 \mathrm{M}$ encompasses most of the transposase binding site and showed a very strong decrease in transposition activity if not complete abolition. (The single $\mathrm{CAT}^{-}$transformant of construct $5 \mathrm{M}$ may represent a recombination event with the distal wild-type end, thus generating wild-type sequence at the internal end; see Materials and methods). $4 \mathrm{M}$ changes 5 of the 16 nucleotides of the transposase binding site and also resulted in a decrease in transposition activity but to a lesser extent than 5M. Preliminary binding studies indicate that mutants $4 \mathrm{M}$ and $5 \mathrm{M}$ impair DNA binding of transposase (P. Kaufman and D. Rio, unpubl.).

\section{$A 5^{\prime}$ end cannot function as $a 3^{\prime}$ end and induces aberrant transposition events}

The ends of many bacterial transposable elements can function interchangeably. That is, two left or right termini of the transposon can function together in transposition, despite, in the cases of IS10 and IS50, apparent differences in the sequences required at the two ends (Foster et al. 1981; Johnson and Reznikoff 1983; Way and Kleckner 1984; Gamas et al. 1985; Morisato and Kleckner 1987). The clustered-point-mutation analysis revealed sequence requirements at the 3 ' end that include the 11- and 31-bp IRs that are common sequences to both the 5' and 3' P-element ends, but it additionally demonstrated a requirement for sequences unique to the 3 ' P-element end. To determine if the $5^{\prime}$ end has sequences that function similarly to those at the $3^{\prime}$ end, we placed a $5^{\prime}$ end in inverted orientation at the proximal 3'-end position in Cgl-3'dup yielding plasmid Cg1-5'5'3' (Fig. 5a).

Analysis of the Cg1-5'5'3' transformants by DNA blot analysis indicated that the internal $5^{\prime}$ end could not function as a $3^{\prime}$ end, but it could induce aberrant transposition events. This contrasts with our results using constructs with two $3^{\prime}$ ends in which we never observed aberrant transposition events. Three of the eight $\mathrm{CAT}^{+}$ $\mathrm{Cg} 1-5^{\prime} 5^{\prime} 3^{\prime}$ lines analyzed had the structure predicted for transposition events occurring with the external $5^{\prime}$ and 3 ' ends (Fig. 5). This is the expected class if the internal $5^{\prime}$ end is totally inactive. The remaining transformant lines represent aberrant transposition events. One $\mathrm{CAT}^{+}$line contained slight abnormalities that we do not understand. The remaining four $\mathrm{CAT}^{+}$transformant lines contained the pUC vector plasmid sequences located outside the P-element ends, in addition to all the expected rosy, CAT, and P-element sequences (Fig. 5b). The external $5^{\prime}$ end appeared to be colinear with pUC vector sequences, whereas the internal $5^{\prime}$ end was adjacent to genomic sequences. These four lines appear to represent a reproducibly occurring aberrant event with Cgl-5' $5^{\prime} 3^{\prime}$. The single CAT ${ }^{-}$line contained the internal $5^{\prime}$ end, but it lacked the external $5^{\prime}$ end, and the frag- ment containing the rosy gene appeared to be truncated at its $5^{\prime}$ end (Fig. 5b). Thus, the two $5^{\prime}$ ends did not function together in a normal transposition event. In the last two classes of aberrant events it appeared as though the internal $5^{\prime}$ end initiated transposition. Transposition complexes might form at the internal $5^{\prime}$ end and search for a correctly oriented $3^{\prime}$ end. In its absence, aberrant transposition events might occur. Regardless of the mechanism of the aberrant events, the $5^{\prime}$ end cannot function as a $3^{\prime}$ end and thus the two ends are not equivalent.

\section{The 8-bp target-site duplication is not required for transposition}

P elements generate an 8-bp target-site duplication upon integration. The target duplication is believed to result from the generation of a double-stranded staggered cut in the target DNA during the initiation of transposition by the transposase protein (Kleckner 1979; Reed et al. 1979|. Unlike the bacterial transposons, P elements are capable of undergoing relatively high rates of transposase-dependent precise excision (for review, see Engels 1989), which suggests a relationship between excision and transposition. Precise excision regenerates a single copy of the target duplication, thus returning the integration site to its original sequence. We have asked whether the 8-bp target-site duplication plays an essential role in forward transposition. We have tested a construct, Cgl-3'dupABA, which has a different 8 bp flanking the proximal $3^{\prime}$ end as shown schematically in Figure 6. If it is important that the two P-element ends have the same $8 \mathrm{bp}$ flanking them, then an increase in the use of the distal 3 ' end should be observed compared to the Cgl-3'dup control. The results show that the distal $3^{\prime}$ end was not used at a significantly higher frequency (Fig. 6) and thus the 8-bp target-site duplication plays little or no role in forward transposition. Similar results were found for several of the bacterial transposons (Johnsrud et al. 1978; Kleckner 1979; Ohtsubo et al. 1979; Johnson and Reznikoff 1983).

\section{Conclusions}

We have carried out a detailed molecular analysis of the cis-acting DNA sequences required for a eukaryotic transposon outside the retrotransposon class of elements. The cis-acting sequences defined for efficient Pelement transposition do not place $P$ elements in any of the bacterial transposon classes characterized, although $P$ elements share some characteristics of a number of different bacterial elements. Similar to other transposons analyzed, the terminal IR is required for transposition. For many transposons these are the only sequences necessary for transposition and are believed to be the DNA binding sites for transposase, as has been shown for $\gamma \delta$ transposase (Wiater and Grindley 1988). Pelement transposase, however, appears to bind sequences internal to the terminal IR and a Drosophila host protein binds a region within the 31 -bp IR. For a 

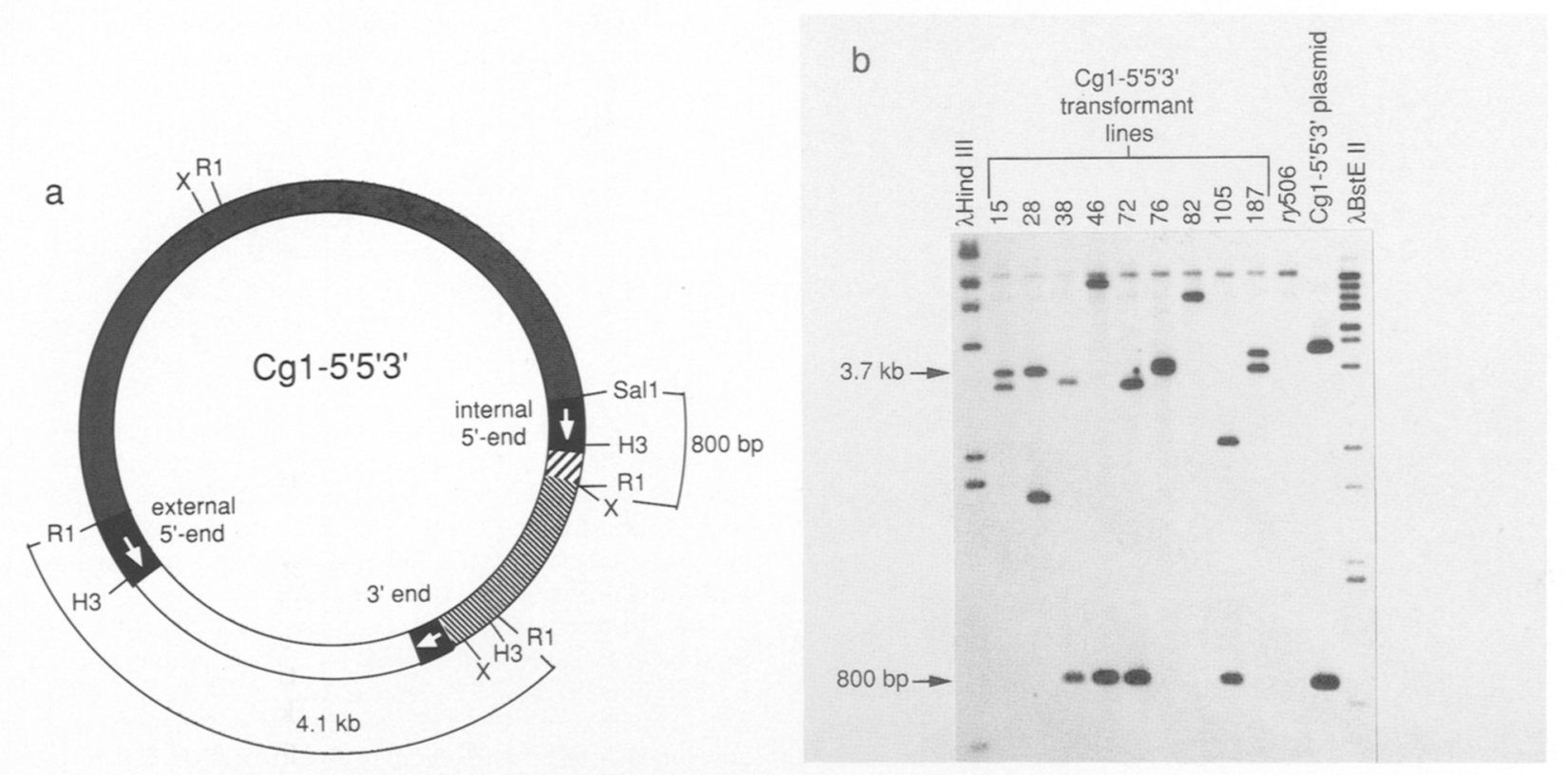

Figure 5. Analysis of the abilities of a $5^{\prime}$ end to function as a $3^{\prime}$ end. (a) A diagram of the plasmid Cg1-5'5'3' is shown. (R1) EcoRI, (H3) HindIII, SalI, and (X) XhoI restriction sites are indicated. Black regions represent P-element end sequences; white arrows indicate the orientation of the 31-bp IR. rosy is indicated by gray; Drosophila genomic sequence is indicated by thick stripes; and the hsCAT gene is indicated by thin stripes. Only 1 of the 10 transformants of this construct did not contain CAT activity. $(b)$ Genomic DNA from nine of the Cgl-5' $5^{\prime} 3^{\prime}$ transformant lines was analyzed by DNA blot hybridization. Shown is EcoRI-SalI-digested genomic DNA hybridized with an 800-bp probe containing the EcoRI-SalI internal $5^{\prime}$ end (indicated in $a$ ). The expected class of CAT ${ }^{+}$transformants that used the external $5^{\prime}$ end and the $3^{\prime}$ end should contain the 800-bp EcoRI-Sall internal $5^{\prime}$ end and a second band of unknown length containing the external 5' end and adjacent genomic DNA. This was found for four CAT ${ }^{+}$lines: $38,46,72$, and 105. The band at about $10 \mathrm{~kb}$ was found in all the genomic DNA and represents hybridization to the $300 \mathrm{bp}$ of Drosophila genomic DNA found in the probe (see $a$ ). Abnormalities were observed, however, in line 72 when a blot of EcoRI-SalI-HindIII-digested DNA was probed with the $5^{\prime}$ end (data not shown). Four of the remaining transformant lines $(15,28,76,187)$ appeared to integrate in the same aberrant manner. Each contained two bands that hybridized to the $5^{\prime}$-end probe, one of $3.7 \mathrm{~kb}$ and a second band of varying length. (In transformant 76, the band at $3.7 \mathrm{~kb}$ is actually a doublet of $3.7 \mathrm{~kb}$ and $3.9 \mathrm{~kb}$ as observed on shorter exposures.) When this blot was reprobed with a DNA fragment containing the pUC ampicillin gene, the $3.7-\mathrm{kb}$ band in these transformants showed hybridization with the ampicillin gene (data not shown). DNA blots of XhoI and XhoI-HindIII digests probed separately with the $5^{\prime}$ end and ampicillin gene confirmed the colinearity between the external $5^{\prime}$ end and the pUC sequences in transformant lines $15,28,76$, and 187 . These blots, in addition to an EcoRI-SalI-HindIII digest blotted and probed with the $5^{\prime}$ end, also indicated that the second band of varying length in the EcoRI-SalI blot contains the internal $5^{\prime}$ end adjacent to genomic DNA. Note that the external $5^{\prime}$ end of the Cg1-5' $5^{\prime} 3^{\prime}$ plasmid is contained in a $4.1-\mathrm{kb}$ fragment in the blot shown. Therefore, the colinearity of the external $5^{\prime}$ end and the pUC sequences in the $3.7-\mathrm{kb}$ band does not extend to the EcoRI site in the CAT gene. A single band of $\sim 7 \mathrm{~kb}$ appeared in the CAT- transformant line 82 on the blot shown. An EcoRI-SalI-HindIII digest blotted and probed separately with the $5^{\prime}$ end and the rosy gene indicated that the internal $5^{\prime}$ end was present, the external $5^{\prime}$ end was absent, and the 3.0-kb rosy fragment was truncated in line 82 . The first and last lanes are ${ }^{32}$ P-labeled bacteriophage $\lambda$ HindIII and BstEII markers, respectively.

number of bacterial transposons, sequences just internal to the IR also have important cis-acting functions and include binding sites for IHF and dnaA protein /Gamas et al. 1985, 1987; Morisato and Kleckner 1987; Phadnis and Berg 1987; Wiater and Grindley 1988). The P-element $3^{\prime}$ end also includes cis-acting sequences beyond the terminal IR but they are far more extensive than those in the transposons just described. In this respect, $\mathrm{P}$ elements resemble the phage $\mathrm{Mu}$, although $\mathrm{Mu}$ does not contain IRs and it has several transposase-binding sites at each end. Unique to P elements is a perfect 11-bp IR located internal to the ends which we determined to be functionally important at the $3^{\prime}$ end.

Additionally, we found that the $5^{\prime}$ end could not function as a $3^{\prime}$ end. Thus, P-element transposition must occur in an asymmetric fashion with respect to the functions of the two ends. Most bacterial transposon ends function equivalently, although, differential transposition activity between the two ends has been observed with a number of transposable elements including IS50, IS10, and IS903 (Sasakawa and Berg 1982; Morisato and Kleckner 1984; Roberts et al. 1985; Derbyshire et al. 1987; Phadnis and Berg 1987). The internal 5' P-element end in $\mathrm{Cg} 1-5^{\prime} 5^{\prime} 3^{\prime}$, however, was not inactive but rather induced aberrant transposition events. Phage $\mathrm{Mu}$ also shows a nonequivalence in the functions of its two ends (Faelen et al. 1979).

The complex sequence elements we defined imply a requirement for a multiplicity of host factors. Such a requirement could explain the absence of transposition 


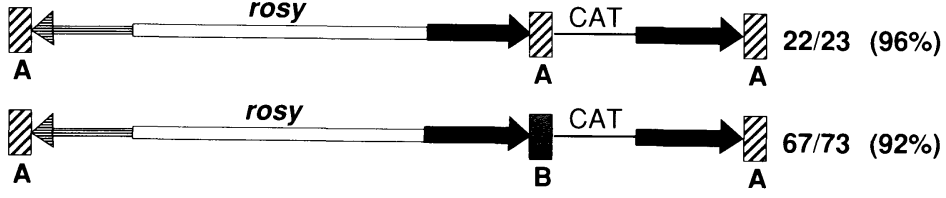
isolated from a different genomic location (see Materials and methods) and thus has a different 8 bp adjacent to it, ATACACAC, site B (stippled box). The $8 \mathrm{bp}$ at sites A and B differ in 6 of 8 positions. At the right of each construct is indicated the fraction of transformants using the proximal $3^{\prime}$ end with the corresponding percentage in parentheses.

Figure 6. Transpositional activity of a P element with different flanking target sites. At the top is shown the Cgl-3'dup vector with P-element ends all derived from the same transposon and therefore having the same $8 \mathrm{bp}$ flanking them, GTCTGGCC, site A (striped box). Below observed when $\mathrm{P}$ elements are introduced into organisms outside of Drosophilidae (Miller et al. 1987; Engels 1989; Rio et al. 1988).

\section{Materials and methods}

\section{Plasmid constructions}

Cg1-3'dup/Cg1-3'dupABA Carnegie 1 (Rubin and Spradling 1983) was digested with PstI, made blunt with T4 DNA polymerase, and ligated with $\mathrm{XbaI}$ linkers yielding $\mathrm{Cg} 1-\mathrm{Xba}$. Carnegie 4 was digested with $A p a I$, made blunt with T4 DNA polymerase, and ligated with SalI linkers. The 300-bp SalI fragment containing the $3^{\prime}$ P-element end from this plasmid was then subcloned into the SalI site of $\mathrm{Cgl}-\mathrm{Xba}$. Into this plasmid was inserted a 2-kb $X b a I$ fragment containing an hsp70 promoter fused to a bacterial CAT gene (the fragment was derived from a plasmid provided by C. Thummel and D. Hogness). Finally, the 7-kb HindIII fragment containing the rosy gene (Rubin and Spradling 1983) was made blunt using DNA polymerase I (Klenow fragment) and inserted into the SmaI site of this plasmid to yield the plasmid $\mathrm{Cg} 1-3$ 'dup. $\mathrm{Cg} 1-3$ 'dupABA was made exactly as described above except that the $3^{\prime}$ P-element end was subcloned from $\mathrm{p} \pi 25.7$ (Karess and Rubin 1984), as follows: $\mathrm{p} \pi 25.7$ was digested with $\mathrm{XbaI}$, made blunt with the Klenow fragment of DNA polymerase, and ligated with SalI linkers. The 3' P-element end was then subcloned as an 762-bp Sall fragment into the SalI site of $\mathrm{Cg} 1-\mathrm{Xba}$ as above.

Cg1-3'dup deletion mutants and clustered-point mutants The proximal 3' P-element end in Cgl-3'dup was removed by digestion with SalI and religation. Then the resultant plasmid was digested partially with $X b a I$, treated with Bal31 enzyme, and religated, thus removing the $\mathrm{XbaI}$ and HindIII polylinker sites between the CAT gene and the distal 3' end. This Cg1-3'dup module contains unique SalI and XbaI sites within which the 3' P-element-deletion mutants and clustered-point mutants were cloned directionally.

The 275-bp HindIII-SalI fragment containing the internal 3' P-element end from $\mathrm{Cg} 1-3$ 'dup was made blunt with Klenow DNA polymerase and subcloned into the SmaI site of pIC-19H (Marsh et al. 1984) yielding pIC-C43'. To make deletion mutants of the $3^{\prime}$ end, pIC-C43' was digested with SalI, partially digested with Bal31 exonuclease, and then cleaved with $X b a I$. The resultant blunt/XbaI fragment was cloned into the plasmid Cg1-3'dup, which had been digested with Sall, Klenow treated, and then $\mathrm{XbaI}$ digested. The sizes of the deletions were estimated on $2 \%$ agarose gels and the deletion endpoints were sequenced by the method of Maxam and Gilbert (1977). Spacer 1, a 1.25-kb BamHI-Sall fragment of bacteriophage $\lambda$ DNA, was placed between the rosy DNA fragment and the 126-bp deletion endpoint in a three-way ligation with a 175-bp BamHI-XbaI fragment containing the deletion end and the SalI-XbaI-digested Cg1-3'dup module. Spacer 2, a 784-bp BamHI-HindIII is shown Cg1-3'dupABA, which has a proximal $3^{\prime}$ end

fragment of $\lambda$ DNA, was ligated in a three-way reaction with the same BamHI-XbaI deletion end fragment and HindIIIXbaI-digested BlueScript (Stratagene, San Diego, California). From the resultant plasmid, spacer 2 and the 126-bp deletion end were subcloned as a 950-bp SalI-XbaI fragment into the SalI-XbaI digested Cg1-3'dup module.

The clustered-point mutants were made according to the method of Haltiner et al. (1985). To make deletions in the $3^{\prime}$ to $5^{\prime}$ direction of the $3^{\prime}$ P-element end, a 300 -bp HindIII-BglII fragment from pIC-C43' containing the $3^{\prime}$ P-element end was subcloned into HindIII-BamHI digested pBRN/B (Haltiner et al. 1985). Deletions in the $5^{\prime}$ to $3^{\prime}$ direction were made from a pBRN/BXba plasmid containing the BamHI-XbaI 3' P-element end from pIC-C43'. pBRN/BXba contains an $\mathrm{XbaI}$ linker at the ClaI site of pBRN/B. Deletions were sized on $2 \%$ agarose gels and sequenced essentially as in Haltiner et al. (1985). This method generated a series of $3^{\prime}$ P-element end deletions in the $5^{\prime}$ or $3^{\prime}$ direction in two different sets of plasmids. Deletion endpoints in either direction are abutted to a BglII restriction site. P-element 3 '-end derivatives with $5^{\prime}$ - and $3^{\prime}$-deletion endpoints separated by $10 \pm 1 \mathrm{bp}$ were joined at their BglII sites and ligated in a three-way reaction into the SalI-XbaI digested Cg1-3'dup module, thus creating clustered-point mutants with the sequence CGAGATCTCG. These mutants include: $3,8,9$, $10,15,20$, and 22 . P-element 3 '-end derivatives with $5^{\prime}$ - and $3^{\prime}$-deletion endpoints separated by $14 \pm 1$ bp were joined at their Klenow filled-in BglII ends in a three-way ligation reaction as above, generating clustered-point mutants with the sequence CGAGATCGATCTCG. These mutants include: 1, 2, 17,31 , and 38 . Occasionally, the terminal $G$ nucleotide in the mutant sequence was absent resulting in the replacement of P-element sequences with CGAGATCTC in mutant 20 and CGAGATCGATCTC in mutants 2 and 31 . Small deletions were made by joining the appropriate spaced $5^{\prime}$ and $3^{\prime}$ deletions at their $B g I I I$ sites as described above. These mutants include: 89-F5, 59-F5, 89-C5, 89-C1, E11-76, E11-D2, E9-C1, 26, and 30. E9- $\mathrm{Cl}$ deletes all $3^{\prime}$ P-element sequences to nucleotide 126. The positions of all other clustered-point mutants are described in Figure $4 a$.

The clustered-point mutants 1M (CGTCTAGCTGA), 2M (GGCTGTCACC), 3M (TAGCAATGGT), 4M (ATGCTTCCAG), and 5M (CACTACGCAA) were made by M13 sitespecific mutagenesis according to standard procedures (Hutchison et al. 1978; Razin et al. 1978; Kudo et al. 1981). The positions of the mutations in the 3 ' end are shown in Figure 4a.

Cg1-5'5' $3^{\prime}$ A SalI-XbaI fragment containing 501 bp of the 5' P-element end from $\mathrm{p} \pi \mathbf{2 5 . 7}$ was subcloned into SalI-XbaI digested $\mathrm{Cg} 1-3^{\prime}$ dup module yielding $\mathrm{Cg} 1-5^{\prime} 5^{\prime} 3^{\prime}$.

\section{P-element transformation lines}

Transformation of $r y^{506} \mathrm{M}$-strain embryos was essentially as described by Karess and Rubin (1984) except higher concentra- 
tions of helper plasmids $\mathrm{p} \pi 25.7 \mathrm{wc}$ or pUChs $\pi \Delta 2-3$ (D. Rio, unpubl.) (100-250 $\mu \mathrm{g}$ ) and the P-element test constructs (500-800 $\mu \mathrm{g})$ were coinjected. Transformation frequencies ranged from about $6 \%$ to $40 \%$ of the fertile $G_{0}$ adult flies. The average transformation frequency of $20 \%$ was the same for constructs in which the internal $3^{\prime}$ P-element end was functional or nonfunctional in transposition. Chromosomal DNA from the transformant lines was isolated by a rapid small-scale procedure as in Steller and Pirrotta (1986). DNA blotting was carried out essentially as in Maniatis et al. (1982). Thirty-four transformant lines of various clustered-point mutants were analyzed by DNA blotting to determine the frequency of recombination between the two $3^{\prime}$ ends such that the wild-type sequence was generated at the proximal 3 '-end position. Only one of the 34 lines was a recombinant. Thus, the frequency of this event is low enough so as not to affect the overall results of our analyses.

\section{CAT assays}

CAT assays were performed essentially as described by Mismer and Rubin (1987). One to five flies of a transformant line were assayed for CAT activity. Generally, CAT reactions were carried out for $2-4 \mathrm{hr}$ at $37^{\circ} \mathrm{C}$, which permitted the CAT reaction to go to completion. We estimated that the limit of detection of our assay was at least $5 \%$ of the level seen in the typical CAT ${ }^{+}$ line.

\section{Acknowledgments}

We thank Carl Thummel for providing the hsp70 CAT plasmid. We thank Richard Carthew, Bill Engels, Janice Fischer, Joe Heilig, and Donald Morisato for critical reading of the manuscript, and other members of the Rubin lab for help and advice. This work was supported by a grant from the National Institutes of Health to G.M.R.

\section{References}

Benjamin, H. W. and N.R. Cozzarelli. 1988. Isolation and characterization of the Tn3 resolvase synaptic intermediate. EMBO I. 7: 1897-1905.

Benjamin, H.W., M.M. Matzuk, M.A. Krasnow, and N.R. Cozzarelli. 1985. Recombination site selection by Tn3 resolvase: Topological tests of a tracking mechanism. Cell 40: $147-158$.

Bingham, P.M., M.G. Kidwell, and G.M. Rubin. 1982. The molecular basis of P-M hybrid dysgenesis: The role of the P element, a P strain-specific transposon family. Cell 29: 9951004.

Craigie, R. and K. Mizuuchi. 1986. Role of DNA topology in Mu transposition: mechanism of sensing the relative orientation of two DNA segments. Cell 45: 793-800.

Craigie, R., M. Mizuuchi, and K. Mizuuchi. 1984. Site-specific recognition of the bacteriophage $\mathrm{Mu}$ ends by the $\mathrm{Mu}$ A protein. Cell 39: 387-394.

Craigie, R., D.J. Arndt-Jovin, and K. Mizuuchi. 1985. A defined system for the DNA strand-transfer reaction at the initiation of bacteriophage $\mathrm{Mu}$ transposition: Protein and DNA substrate requirements. Proc. Natl. Acad. Sci. 82: 75707574.

Derbyshire, K.M., L. Hwang, and N.D.F. Grindley. 1987. Genetic analysis of the interaction of the insertion sequence IS903 transposase with its terminal inverted repeats. Proc. Natl. Acad. Sci. 84: 8049-8063.

Engels, W.R. 1989. P elements in Drosophila. In Mobile DNA (ed. D. Berg and M. Howe). American Society for Microbiology (in press).

Faelen, M., A. Toussaint, and A. Résibois. 1979. Mini-muduction: A new mode of gene transfer mediated by mini-Mu. Mol. Gen. Genet. 176: 191-197.

Foster, T.J., M.A. Davis, D.E. Roberts, K. Takeshita, and N. Kleckner. 1981. Genetic organization of transposon Tn10. Cell 23: 201-213.

Gamas, P., D. Galas, and M. Chandler. 1985. DNA sequence at the end of IS1 required for transposition. Nature 317: 458460.

Gamas, P., M.G. Chandler, P. Prentki, and D.J. Galas. 1987. Escherichia coli integration host factor binds specifically to the ends of the insertion sequence IS1 and to its major insertion hot-spot in pBR322. J. Mol. Biol. 195: 261-272.

Grindley, N.D.F. and R.R. Reed. 1985. Transpositional recombination in prokaryotes. Annu. Rev. Biochem. 54: 863-896.

Groenen, M.A.M., E. Timmers, and P. van de Putte. 1985. DNA sequences at the ends of the genome of bacteriophage $\mathrm{Mu}$ essential for transposition. Proc. Natl. Acad. Sci. 82: 20872091.

Haltiner, M., T. Kempe, and R. Tjian. 1985. A novel strategy for constructing clustered point mutations. Nucleic Acids Res. 13: $1015-1025$.

Hutchison, C.A., S. Phillips, M.H. Edgell, S. Gillam, P. Jahnke, and M. Smith. 1978. Mutagenesis at a specific position in a DNA sequence. J. Biol. Chem. 253: 6551-6560.

Johnson, R. C., and S. Reznikoff. 1983. DNA sequences at the ends of transposon $\mathrm{Tn} 5$ required for transposition. Nature 304: 280-282.

Johnsrud, L., M.P. Calos, and J.H. Miller. 1978. The transposon $\mathrm{Tn} 9$ generates a $9 \mathrm{bp}$ repeated sequence during integration. Cell 15: 1209-1219.

Karess, R.E. and G.M. Rubin. 1984. Analysis of P transposable element functions in Drosophila. Cell 38: 135-146.

Kitts, P.A., L.S. Symington, P. Dyson, and D.J. Sherrat. 1983. Transposon-encoded site-specific recombination: Nature of the Tn3 DNA sequences which constitute the recombination site res. $E M B O$ J. 2: 1055-1060.

Kleckner, N. 1979. DNA sequence analysis of Tn10 insertions: Origin and role of 9 bp flanking repetitions during Tn10 Translocation. Cell 16: 711-720.

- 1981. Transposable elements in prokaryotes. Annu. Rev. Genet. 15: 341-404.

Krasnow, M.A. and N.R. Cozzarelli. 1983. Site-specific relaxation and recombination by the Tn3 resolvase: Recognition of the DNA path between oriented res sites. Cell 32: 13131324.

Kudo, I., M. Leineweber, and U.L. RajBhandary. 1981. Site-specific mutagenesis on cloned DNAs: generation of a mutant of Escherichia coli tyrosine suppressor tRNA in which the sequence G-T-T-C corresponding to the universal G-T-II-C sequence of tRNAs is changed to G-A-T-C. Proc. Natl. Acad. Sci. 78: 4753-4757.

Laski, F.A., D.C. Rio, and G.M. Rubin. 1986. Tissue specificity of Drosophila P element transposition is regulated at the level of mRNA splicing. Cell 44: 7-19.

Maniatis, T., E.F. Fritsch, and J. Sambrook. 1982. Molecular Cloning: A laboratory manual. Cold Spring Harbor Laboratory, Cold Spring Harbor, New York.

Marsh, J.L., M. Erfle, and E.J. Wykes. 1984. The pIC plasmid and phage vectors with versatile cloning sites for recombinant selection by insertional inactivation. Gene 32: 481485.

Maxam, A.M. and W. Gilbert. 1977. A new method for sequencing DNA. Proc. Natl. Acad. Sci. 74: 560-564.

Miller, L.H., R.K. Sakai, P. Romans, R.W. Gwadz, P. Kantoff, 
and H.G. Coon. 1987. Stable integration and expression of a bacterial gene in the mosquito Anopheles gambiae. Science 237: 779-781.

Mismer, D. and G.M. Rubin. 1987. Analysis of the promoter of the ninaE opsin gene in Drosophila melanogaster. Genetics 116: $565-578$.

Morisato, D. and N. Kleckner. 1984. Transposase promotes double strand breaks and single strand joints at Tn10 termini in vivo. Cell 39: 181-190.

. 1987. Tn10 transposition and circle formation in vitro. Cell 51: 101-111.

O'Hare, K. and G.M. Rubin. 1983. Structures of P transposable elements and their sites of insertion and excision in the Drosophila melanogaster genome. Cell 34: 25-35.

Ohtsubo, H., H. Ohmori, and E. Ohtsubo. 1979. Nucleotide sequence analysis of Tn3: implications for insertion and deletion. Cold Spring Harbor Symp. Quant. Biol. 43: 12691277.

Phadnis, S.H. and D.E. Berg. 1987. Identification of base pairs in the outside end of insertion sequence IS50 that are needed for IS50 and Tn5 transposition. Proc. Natl. Acad. Sci. 84: 9118-9122.

Razin, A., T. Hirose, K. Itakura, and A.D. Riggs. 1978. Efficient correction of a mutation by use of chemically synthesized DNA. Proc. Natl. Acad. Sci. 75: 4268-4270.

Reed, R.R., R.A. Young, J.A. Steitz, N.D.F. Grindley, and M.S. Guyer. 1979. Transposition of the Escherichia coli insertion element gamma delta generates a five-base-pair repeat. Proc. Natl. Acad. Sci. 76: 4882-4886.

Rio, D.C. and G.M. Rubin. 1988. Identification and purification of a Drosophila protein that binds to the terminal 31 basepair inverted repeats of the $P$ transposable element. Proc. Natl. Acad. Sci. 85: 8929-8933.

Rio, D.C., F.A. Laski, and G.M. Rubin. 1986. Identification and immunochemical analysis of biologically active Drosophila P element transposase. Cell 44: 21-32.

Rio, D.C., G. Barnes, F.A. Laski, J. Rine, and G.M. Rubin. 1988. Evidence for Drosophila $P$ element transposase activity in mammalian cells and yeast. J. Mol. Biol. 200: 411-415.

Roberts, D., B.C. Hoopes, W.R. McClure, and N. Kleckner. 1985. IS10 transposition is regulated by DNA adenine methylation. Cell 43: 117-130.

Rubin, G.M. and A.C. Spradling. 1983. Vectors for P elementmediated gene transfer in Drosophila. Nucleic Acids Res. 11: $6341-6351$.

Rubin, G.M., M.G. Kidwell, and P.M. Bingham. 1982. The molecular basis of P-M hybrid dysgenesis: The nature of induced mutations. Cell 29: 987-994.

Sasakawa, C. and D.E. Berg. 1982. IS50-mediated inverse transposition. Discrimination between the two ends of an IS element. J. Mol. Biol. 159: 257-271.

Shapiro, J.A. 1983. Mobile genetic elements. Academic Press, New York.

Spradling, A.C. 1986. P element-mediated transformation. In Drosophila a practical approach (ed. D.B. Roberts). pp. 175-197. IRL Press, Oxford.

Steller, H. and V. Pirrotta. 1986. P transposons controlled by the heat shock promoter. Mol. Cell. Biol. 6: 1640-1649.

Wiater, L.A. and N.D.F. Grindley. 1988. $\gamma \delta$ transposase and integration host factor bind cooperatively at both ends of $\gamma \delta$. EMBO I. 7: 1907-1911.

Wasserman, S.A., J.M. Dungan, and N.R. Cozzarelli. 1985. Discovery of a predicted DNA knot substantiates a model for site-specific recombination. Science 229: 171-174.

Way, J.C. and N. Kleckner. 1984. Essential sites at transposon Tn10 termini. Proc. Natl. Acad. Sci. 81: 3452-3456.
Weiner, A.M., P.L. Deininger, and A. Efstratiadis. 1986. Nonviral retroposons: genes, pseudogenes and transposable elements generated by the reverse flow of genetic information. Annu. Rev. Biochem. 55: 631-661.

Weinert, T.A., N.A. Schaus, and N.D.F. Grindley. 1983. Insertion sequence duplication in transpositional recombination. Science 222: 755-765. 




\section{cis-acting DNA sequence requirements for P-element transposition.}

M C Mullins, D C Rio and G M Rubin

Genes Dev. 1989, 3:

Access the most recent version at doi:10.1101/gad.3.5.729

References This article cites 48 articles, 17 of which can be accessed free at:

http://genesdev.cshlp.org/content/3/5/729.full.html\#ref-list-1

License

Email Alerting Receive free email alerts when new articles cite this article - sign up in the box at the top Service right corner of the article or click here.

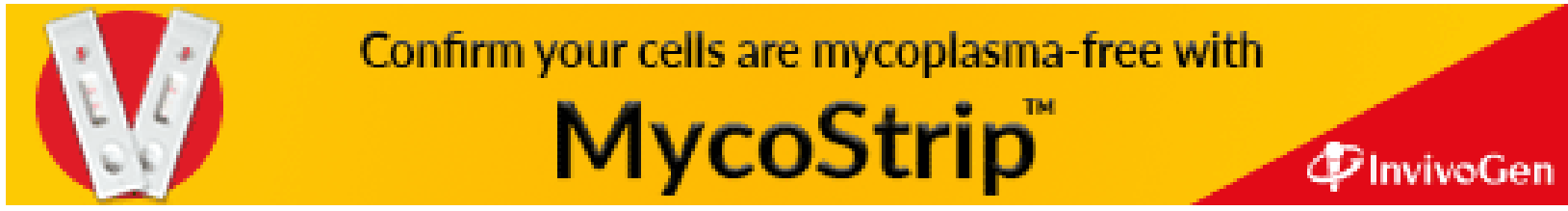

